\title{
SABERES POSSÍVEIS NO PROCESSO DE ENSINAR E APRENDER DANÇA: REVISITANDO BASES EPISTEMOLÓGICAS
}

\author{
Neusa Dendena Kleinubing, Universidade Comunitária da Região de Chapecó - Chapecó, \\ Santa Catarina - Brasil \\ Maria do Carmo Saraiva, Universidade Federal de Santa Catarina - UFSC, Santa Catarina - \\ Brasil \\ Damiana Fernandes de Melo, Escola Angel Vianna, Rio de Janeiro - Brasil
}

\begin{abstract}
RESUMO
Este ensaio tem por objetivo discutir a dança e os possíveis conhecimentos que podem ser apreendidos a partir da sua prática. Nesse sentido, empreendemos esforços a fim de problematizar e identificar os saberes, bem como bases dos pensamentos geradores desses, refletindo sobre as implicações de tais formas de pensar e fazer a dança em diferentes contextos nas quais esta se manifesta. Para isso discutimos a dança a partir de três momentos históricos que retratam diferentes realidades político-sociais e procuramos identificar modos de pensar a sociedade, o sujeito que dança e a própria dança. Entendemos que esse caminho amplia o olhar sobre essa prática, possibilitando construir conhecimentos que dão conta de compreender a diversidade e a complexidade humana. Almejamos com esse texto (re)discutir as contribuições da dança no processo de formação humana, com especial atenção para a dança na escola, no contexto da Educação Física.
\end{abstract}

Palavras-Chave: Dança; Epistemologia; Educação Física.

\section{POSSIBLE KNOWLEDGE IN THE PROCESS OF TEACHING AND LEARNING DANCE: RE-VISITING EPISTEMOLOGY BASES}

\begin{abstract}
This essay aims to discuss the dance and the possible knowledge that can be seized from its practice. In this sense, we discuss and identify the different knowledge domains, as well as the base of the generators of these thoughts, reflecting the implications of such forms of thinking and doing dance in different contexts in which it is manifested. Thus, we discuss dance and matters related to dance under three historical perspectives that reflect different political and social realities; we also seek to identify ways of thinking society, the dancing subject, and dance itself. We understand that taking this path allows us to have a broader outlook on the dance practice so that we can better understand human diversity and complexity. With this text, we aim to (re)discuss the contributions of this body practice in the process of human formation, presenting opportunities to situate it in the context of Physical Education.
\end{abstract}

Key-Words: Dance, Epistemology, Physical Education. 


\section{CONOCIMIENTO POSIBLE EN EL PROCESO DE ENSEÑANZA Y APRENDIZAJE DE DANZA: REVISAR LOS FUNDAMENTOS EPISTEMOLÓGICOS}

\section{RESUMEN}

Este ensayo tiene como objetivo discutir la danza y el posible conocimiento que se puede aprender de su práctica. En este sentido, nos esforzamos en identificar los conocimientos y preguntas, así como las bases de la generación de tales pensamientos, reflexionando sobre las implicaciones de tales formas de pensar y hacer la danza en diferentes contextos en que se manifiesta. Para discutir esta danza a partir de tres momentos históricos diferentes que retratan la realidad política y social y tratar de identificar las maneras de pensar acerca de la sociedad, el hombre que danza y el danza en sí mismo. Entendemos que esta ruta se amplía la visión de esta práctica, lo que permite el conocimiento necesario para entender la diversidad humana y la complejidad. Nuestro objetivo con este texto (re) para discutir las contribuciones de la danza en el proceso de desarrollo humano, con especial atención a la escuela de danza en el contexto de la Educación Física.

Palabras-Clave: Danza; Epistemologia; Educacion Fisica. 


\section{INTRODUÇÃO}

Sabemos que todo processo de ensino-aprendizagem está ancorado numa forma de pensar o mundo e o ser humano, que podemos chamar de matrizes de pensamentos. Nessas matrizes, há indicativos de qual postura o sujeito deve tomar frente ao processo de apreender as coisas do mundo. Assim, paralelo aos conhecimentos que adquirimos ao longo da vida, também aprendemos (ou somos forjados para aprender) formas de ser e estar nesse mundo. Em toda ação que envolve um sujeito que ensina (teoricamente o professor(a)) e um sujeito que aprende (teoricamente o aluno(a)), há uma relação pedagógica, mesmo quando essa ação não ocorre em contextos formais de ensino. Assim, na dança, relações são travadas, tanto em contextos escolares quanto em academias de dança, companhias, grupos, etc. e são essas relações, situadas historicamente e socialmente, que nos interessa pensar, já que são reveladoras de formas de ensinar e aprender dança, de modos de formar sujeitos.

Compreendendo então, que toda prática corporal, inclusive a dança, contribui para construir, desconstruir e reconstruir saberes com relação à própria prática corporal, ao próprio corpo e ao mundo do qual fazemos parte é importante pensar qual é a ideia de corpo, de sujeito, de sociedade e de mundo subjacente às diferentes formas de pensar e fazer dança.

Nisso consideramos importante situá-la no contexto histórico para entender os pensamentos herdados e as implicações na forma de olhar para o mundo e para o sujeito nele inserido. Iniciamos apresentando os ideais estéticos e sociais compreendidos no balé clássico, para depois discutir esses elementos na Dança Moderna e Contemporânea. A escolha dessas estéticas se dá 
devido à sua relação direta com as formas político-sociais de suas épocas, apontando perspectivas estéticas, filosóficas e epistemológicas diferenciadas.

Mesmo estas não surgindo no contexto formal de ensino, seus "ensinamentos" são transferidos para esse contexto, já que a escola "lida" com as coisas do mundo e se apropria dos conhecimentos nele veiculados. Assim, nossa reflexão busca identificar as implicações dessas diferentes formas de pensar a dança no processo de formação humana e qual é sua maior contribuição no contexto da educação física escolar, já que está a cargo dessa disciplina curricular, tratar dos elementos da cultura de movimento, sendo a dança um desses elementos.

\section{NA TRAJETÓRIA DA DANÇA: FORMAS DE SER E ESTAR}

Ainda hoje, quando falamos em dança, é frequente vir à tona a imagem referente ao balé clássico. Em vários estudos como os de Saraiva-Kunz, ${ }^{1}$ Abraão ${ }^{2}$ e Kleinubing ${ }^{3}$ surgem dados que revelam, por um lado, o quanto essa ideia/forma de dança está disseminada no imaginário social e, por outro, as implicações que isso traz no processo de ensinar e aprender.

Segundo Monteiro ${ }^{4}$ o balé foi uma invenção do Renascimento Italiano no século XV, que se difundiu no ocidente nos século XVII e XVIII. Ainda segundo essa autora, a ideia do balé remete às danças executadas num salão de baile por uma elite cortesã; isso significa que a dança já vinha se desenvolvendo no bojo de um processo de refinamento das condutas sociáveis, como atestavam, largamente, os manuais para educação de nobres, em circulação no período. Danças, bailes ou balés implicavam educação do corpo e do gesto. O controle pulsional se dava em função da dinâmica social e política da vida nas cortes. ${ }^{4}$ (p. 171).

A educação do corpo e do gesto pela dança teve singular espaço no reinado de Luis XIV, o Rei Sol, na França do século XVII. Segundo Portinari, ${ }^{5}$ Luis XIV foi a "encarnação da monarquia 
absoluta”. Em 1661, criou a Académie Royale de La Danse, e apresentou o objetivo de tal instituição:

\begin{abstract}
A arte da dança sempre foi reconhecida como uma das artes mais honestas e necessárias para formar o corpo e para lhe dar as primeiras e naturais disposições para todas as espécies de exercícios, entre os quais os das armas, sendo por conseguinte umas das mais vantajosas e úteis à nossa nobreza e às outras pessoas que têm a honra de nos servir, não só em tempo de guerra, mas também em tempo de paz, nos nossos ballets... Desejamos restabelecer a referida arte na sua perfeição e aumentá-la tanto quanto possível. ${ }^{5}$ (p. 66-67).
\end{abstract}

Assim, identifica-se no nascimento do balé, uma pedagogia do corpo que visa atender as exigências ideológicas capazes de darem conta das "novas necessidades da modernidade que se inicia". ${ }^{4}$ (p. 174). Há, nesse processo, uma separação e hierarquização daquilo que é considerado dança e de quem poderia dançá-la. Essa separação e hierarquização fez com que o balé fosse uma arte para poucos e para privilegiados. O processo de fazer balé constituiu-se numa normatização técnica a fim de instituir padrões de execução uniformes, exigente também, de um padrão corporal capaz de realizar tais execuções. Faz-se necessário deixar claro que a aparente crítica ao balé clássico não tem por fim o julgamento de uma expressão estética do corpo, que se constitui, sem dúvida, em objetivo artístico, que "cria tensões continuas e mediações entre quem o cria e o contemplador", ${ }^{1}$ (p. 103) proporcionando, portanto, a quem o contempla a "fruição na sua própria percepção da obra" (p. 103). Trata-se, aqui, de uma compreensão das possibilidades formativas das diferentes formas de dança no processo educacional, particularmente da escola.

Os padrões de movimentos exigidos para a dança, também eram exigidos para o cotidiano da vida na corte de Luis XIV. Segundo Portinari ${ }^{5}$ (p. 68), a etiqueta da sua corte

tinha muito de dança, de marcação preestabelecida, uma espécie de meticulosa coreografia para o dia-a-dia. Todas as atividades da corte eram regulamentadas por intrincado cerimonial da manhã à noite. Ao aproximar-se do monarca, por 
exemplo, um cortesão tinha que obedecer a uma rigorosa contagem de passos antes de fazer a tradicional reverência [...] protocolo e prestígio estavam em jogo. Ninguém podia desrespeitar a etiqueta, fosse num jantar de gala ou numa simples conversa. Até mesmo as expressões faciais e os sorrisos eram codificados.

Essas questões nos ajudam a identificar, nessa forma de fazer dança o pensamento que influenciou, nos últimos quatro séculos (com os resquícios disso percebidos nos tempos atuais), a produção do conhecimento na cultura ocidental, estruturada fundamentalmente por um pensamento que "consiste na classificação e fragmentação dos grandes objetivos em soluções técnicas", conforme discute $\operatorname{Santos}^{6}$ (p. 322). Essa forma de construção do conhecimento, também pode ser reconhecida no processo de formatação do balé quando, ao ser codificado, assume uma das premissas da ciência moderna, qual seja, romper com o conhecimento do senso comum a partir da lei da "causa formal que privilegia o como funciona das coisas em detrimento de qual o agente ou qual o fim das coisas". ${ }^{7}$ (p. 16).

Nessa perspectiva de produtividade que se instaura para todos os âmbitos da vida na modernidade, tornou-se importante codificar, dominar a forma de fazer dança, concedendo autoridade e reconhecimento para quem desfrutasse dessa prática e se apropriasse desse saber distinguindo-o, consequentemente, do restante do corpo social, ou melhor, daqueles que não tendo esse conhecimento, permaneciam no senso comum. Nisso, é possível identificar, como afirma $\operatorname{Santos}^{7}$ que

O determinismo mecanicista é o horizonte certo de uma forma de conhecimento que se pretende utilitário e funcional, reconhecido menos pela capacidade de compreender profundamente o real do que pela capacidade de o dominar e transformar. No plano social, é esse também o horizonte cognitivo mais adequado aos interesses da burguesia ascendente que via na sociedade em que começava a dominar o estádio ( sic) final da evolução da humanidade [...]. (p.17). 
Pensando no processo de ensino e aprendizagem do balé, se há uma forma codificada, um modo “certo" de fazer essa dança, deve haver, também, uma forma de ensinar e aprender que corresponda a essas exigências. Fortin ${ }^{8}$ nos diz que, no ensino da dança, a tradição é uma das principais fontes do saber, e que, apesar da criação coreográfica ter evoluído, o ensino da dança "permaneceu fiel em grande parte aos usos e costumes da tradição" ${ }^{8}$ (p. 163). Também discutindo sobre a forte tradição do ensino da dança $\operatorname{Strazzacappa}^{9}$ (p. 189), afirma que nos estúdios e academias, lugares mais comuns em que a formação em dança acontece,

prevalece a característica da formação oral. O professor realiza o movimento $\mathrm{o}$ aluno imita o gesto. O professor orienta $-\mathrm{o}$ aluno faz. As escolas perpetuam essa metodologia de aprendizagem na qual há sempre um modelo para ser seguido ou obedecido. Os chamados 'mestres' ensinam segundo a maneira como eles, por sua vez, foram ensinados.

Não é difícil encontrarmos professores(as) realizando as clássicas aulas: barra, centro, diagonal, sendo o(a) professor(a), sempre o centro do processo, aquele(a) que deve ser observado(a) e copiado(a) nos seus movimentos e gestos. Essas imagens são as referências que a maioria das pessoas tem ao pensar numa aula de dança, mesmo que não seja de balé, mas sim de dança contemporânea, ou outros gêneros e ou estilos, ${ }^{1}$ aliadas ainda, ao estereótipo sobre a vestimenta necessária para sua realização (malha e sapatilha) e à quase inexistência da figura masculina no espaço da sala de dança. Daí, talvez, o "saber construído" de que dança "é coisa de menina".

Assim, podemos dizer que os conhecimentos apreendidos a respeito dessa forma de dança, que conhecemos por balé, têm a ver com um padrão de movimentos codificados que devem ser seguidos; com uma ordem e dinâmica de aula que devem ser respeitadas; todo o saber referente

\footnotetext{
${ }^{1}$ Entendemos que o gênero da dança refere-se aos objetivos que ela propõe. Assim, podemos falar em dois grandes grupos: a dança de cunho apresentativo ou artístico (dança cênica) e a dança com propósitos de lazer. Já com relação aos estilos de dança nos apoiamos na definição de Houaiss ${ }^{10}$ (p. 314) para qual o estilo "é um conjunto de características formais que identificam uma obra, um artista, etc (...)". Nesse sentido algumas danças apresentam características formais representadas/formatadas por técnicas específicas, o que podemos chamar de estilo, tais como: balé, jazz, sapateado, flamenco, ventre, entre outras.
}

Conexões: revista da Faculdade de Educação Física da UNICAMP, Campinas, v. 9, n. 2, p. 110-129, maio/ago. 2011. ISSN: 1983-9030 
à forma de fazer, será "repassada" por um professor ou por uma professora; os passos do balé “são difíceis" e não podem ser realizados por qualquer pessoa, já que exigem "muita habilidade" e, por fim, a necessidade de ser magra/o para não prejudicar a estética desse estilo de dança.

Dessa forma, também é possível pensar a estrutura do balé clássico como potencializadora das relações de poder - mesmo entendendo-se que qualquer estilo de dança pode ser trabalhado nessa perspectiva - porque a estrutura inerente ao balé clássico, privilegia essa questão. Isso se reflete, por exemplo, quando os professores e as professoras demonstram o movimento, oferecendo-se como imagem referencial, e quando a gestão do corpo dos(as) alunos(as) repousa sobre critérios de apreciação externos a eles(as), conforme discute Fortin. ${ }^{8}$ Ao julgar a partir de referenciais pré-estabelecidos, o(a) professor(a) limita a possibilidade do sujeito que dança se autoconhecer, de investigar no próprio corpo a posição ideal para a execução de determinado movimento, ou ainda, inibe uma postura mais crítica com relação ao fazer/pensar dança. Ainda, nesse sentido, Alves e Saraiva $^{11}$ (s/p.), argumentam que muitas vezes a autoridade do(a) professor(a) reprime o(a) bailarino(a) e este(a) "tende a se tornar apenas um reprodutor da dança, deixando de explorar o seu potencial expressivo e criativo e, ainda, ao obedecer sem questionar, fica impedido de desvendar formas mais adequadas de realizar os movimentos, deixando de gerar outras técnicas inovadoras”.

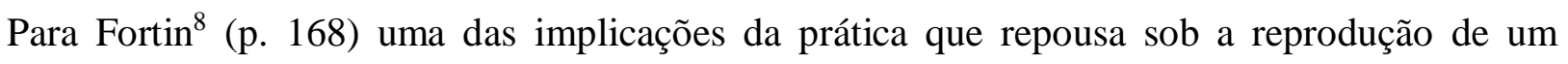
modelo "é que a pessoa nem sempre pode converter o que ela vê naquilo que ela deveria sentir". A autora argumenta

que é desejável que o aluno possa ver o professor demonstrar o que propõe, mas a demonstração do professor deveria idealmente ser acompanhada de estímulos para que o aluno recolha, em sua experiência vivida, os verdadeiros índices que lhe revelarão como reproduzir o que ele viu. A exploração sensível 
da pessoa por ela mesma é uma fonte de saber complementar à dos professores e professoras. (p. 168).

Em contrapartida, na trajetória histórica, surgiram outros modos de pensar e fazer dança. Essas novas ideias estão intrinsecamente ligadas às mudanças no modo de pensar o sujeito na sua relação com o mundo. $\mathrm{O}$ movimento surgido no início do século $\mathrm{XX}$ traz para a cena aquilo que conhecemos como Dança Moderna. Segundo Canton, ${ }^{12}$ a mola propulsora desse pensamento seria o conceito de "vanguarda" um termo de guerra que pressupõe duas ideias básicas: a de se estar "à frente", isto é, de fazer algo novo, e a de "guarda", que se liga à luta, à ruptura. Sendo esses os desejos dos artistas modernos, as bases de todos os movimentos que criaram, independente de suas singularidades, estariam ligadas às noções de novo e de ruptura. Na busca pela criação de obras cada vez mais inovadoras e que pudessem romper com a ordem vigente é que os artistas modernos elaboraram seus movimentos, afinal de contas, pertenciam a uma era tremendamente intensa, que no rastro da revolução industrial, urbanizou cidades, promoveu espantosas inovações tecnológicas, produziu duas guerras mundiais. Nisso, era preciso que a arte se tornasse tão inovadora e radical quanto o momento histórico vivido, manifestando-se o novo, de maneiras muito diversas e particulares, ampliando enormemente as possibilidades artísticas no século XX.

A Dança Moderna foi influenciada, inicialmente, por ideias de pessoas que não eram dançarinos, como Delsarte e Dalcroze. O primeiro investigou as possibilidades do movimento humano e, mesmo sem ter criado nenhum sistema ou método de dança, explorou princípios que se constituíram no ponto de partida da evolução da Expressão Corporal e da Dança Moderna. Esses princípios foram estabelecidos a partir da intensiva observação e classificação das leis que regem o uso do corpo humano como meio de expressão. O segundo investigou a relação de vários ritmos e as diferentes reações nas pessoas com dificuldade de percepção do ritmo Conexões: revista da Faculdade de Educação Física da UNICAMP, Campinas, v. 9, n. 2, p. 110-129, maio/ago. 2011. ISSN: 1983-9030 
musical, a arritmia. Para auxiliar no tratamento dessa dificuldade, Dalcroze criou a euritmia. Os pioneiros da dança moderna perceberam que a anatomia humana possibilitava movimentos outros, além daqueles impostos pelo balé, o que provocou uma mudança radical no modo de fazer dança. De forma breve, podemos dizer que a dança moderna rompeu com inúmeros paradigmas, entre eles, o da existência de uma única forma de fazer dança, e de que é possível uma pessoalidade na dança, isto é, um fazer e pensar dança próprio, na "primeira pessoa".

Essas ideias coadunam-se com o início de um processo de repensar o homem na sua relação com a construção de conhecimento e o mote dessa mudança está em perceber, conforme afirma $\operatorname{Morin}^{13}$ (p. 20), que "o conhecimento não é um espelho das coisas ou do mundo externo. Todas as percepções são, ao mesmo tempo, traduções e reconstruções cerebrais com base em estímulos ou sinais captados e codificados pelos sentidos". Dessa forma, "sintonizando" a complexidade do nosso tempo, a dança, a partir dos seus intérpretes/autores, passa a assumir um caráter provocativo, questionador, reinventando esse outro modo do(s) sujeito(s) ser e estar no mundo, que é a dança. ${ }^{14}$

Assim, do início do século XX até os dias atuais, inúmeras questões foram incorporadas ao fazer dança que exigem uma leitura mais complexa desse fenômeno, e principalmente, outros saberes, para além dos próprios saberes da dança, se fazem necessários na hora de fazê-la e/ou ensiná-la. Nesse sentido, Saraiva-Kunz, ${ }^{1}$ argumenta que a dança

é um fenômeno cultural complexo, cuja abordagem implica um entrecruzamento de suas trajetórias histórica e filosófica, com questões de ordem política, social, antropológica e psicológica, sem o qual o entendimento possível dela seria tendencioso ou reduzido. (p. 79). 
Desse modo a dança passa a abarcar e revelar questões inerentes à condição do sujeito que a realiza emergindo, desse denso panorama sócio-histórico, um corpo que não mais representa ou interpreta, mas um corpo que propõe, cria, é. Podemos encontrar aproximações dessas ideias tanto no contexto das companhias profissionais quanto no contexto da educação formal. Mais especificamente, surgem nesses dois âmbitos questões sobre: que corpo pode dançar? $\mathrm{O}$ que dançar? Como dançar?

Essas discussões se reportam a complexidade do fenômeno da dança implicada com o momento atual que vivemos. Ampliando nossa percepção com relação à dança e ao próprio corpo que dança, afloram nessas questões a necessidade de considerá-la não como uma prática alienada das coisas do mundo, mas sim como prática que questiona, problematiza, pesquisa e (re)inventa esse mundo e, faz surgir no corpo que a vivencia, uma forma particular de agir. Nesse sentido, Lepecki $^{15}$ (p. 8) aponta que alguns coreógrafos contemporâneos vêm contribuindo significativamente para repensar a dança e o corpo dançante em nosso tempo ao rejeitarem "uma relação privilegiada com o corpo laboral emudecido"; também, ao recusarem "estruturas sociais de comando", sugerindo que essas posturas ampliam o papel da dança na arte quando, a partir da sua linguagem específica, é capaz de problematizar e questionar a questão política, social. Nesse aspecto, acreditamos que para dançar, já não basta dominar uma técnica específica, é preciso se apropriar de outros saberes, visualizando e experimentando outras formas de dançar, é preciso ampliar as áreas de conhecimento que possibilitem a cada dançarino(a) a estrutura necessária para que suas ideias e pensamentos possam aparecer em formato de dança, pensando essa prática para além de junções de passos. 
Nessa perspectiva, como pensar os conhecimentos advindos da prática da dança a ser desenvolvida no contexto escolar na contemporaneidade? Que tipos de saberes podemos construir a partir de uma prática que privilegia o sujeito e suas possibilidades de movimento? É realmente necessário ensinar dança na escola? Ainda, antes dessas questões, é preciso perguntar se acreditamos que é possível a qualquer sujeito dançar? A posição tomada em relação a essa última questão orienta toda uma compreensão do processo de fazer dança.

Se tomamos a posição de que não é possível qualquer sujeito dançar, estamos acordando que essa prática está destinada a um grupo especial, com habilidades e competências especiais e, que estas, não são passíveis de serem desenvolvidas por qualquer sujeito. Mas se, ao contrário, acreditamos ser possível a todo sujeito experimentar a dança, então, podemos visualizá-la como processo capaz de potencializar as possibilidades de cada corpo/sujeito. Nesse caminho, surge uma nova e ampla perspectiva ao fazer dança, qual seja, o respeito às possibilidades e limitações de cada corpo e a instauração de diferentes sentidos e significados pelos diferentes corpos que dançam.

Pensando a dança como atividade à que se atribui sentido e significado, evidencia-se a preocupação de como devemos conduzir um trabalho que priorize as experiências individuais de movimento, no sentido de abrir espaço para que novos conhecimentos a respeito da dança, de si mesmo e do mundo possam ser construídos. Vários autores, principalmente aqueles ligados às correntes críticas e feministas, defendem o entendimento de que o sujeito que dança deve estar “ativamente engajado em construir conhecimento e experiência pessoal de valor" na construção/elaboração dessa prática. ${ }^{8}$ (p. 170). 


\section{A CONSTRUÇÃO DE SABERES NA/DA DANÇA: CONTRIBUIÇÕES PARA A FORMAÇÃO HUMANA}

Tomando como ponto de partida a compreensão de que todo sujeito é capaz de dançar a partir das suas condições corporais, e que ao dançar diferentes sentidos e significados vão se constituindo, podemos pensar nos saberes que podem ser construídos a partir dessa perspectiva. Além do saber inerente aos aspectos coreológicos da dança (os aspectos que fazem uma simples série de movimentos converterem-se em gestos de dança), é possível construir um saber ligado ao respeito pelas possibilidades individuais e coletivas, e a necessidade de saber lidar/conviver com as diferentes ideias e posicionamentos. Acreditamos ser possível a construção de um conhecimento que dá conta de compreender a diversidade e a complexidade humana, reveladas pelas formas de ser e estar nesse mundo, totalmente pessoais e únicas, passíveis de serem apresentadas e discutidas pela/na dança. Também a ampliação das experiências em dança possibilita construir novas referências do que podemos chamar de dança e de quem pode realizá-la. ${ }^{3}$

Essas reflexões nos levam a pensar sobre a necessidade do ensino da dança na escola. Considerando as discussões acima, o processo de ensinar dança na escola, se torna imprescindível, já que oportuniza a ampliação da leitura de mundo do sujeito a partir das suas possibilidades de movimento e de envolvimento com a dança, provocando situações de autoconhecimento e de (re)conhecimento dos modos de ser e estar de outros corpos/sujeitos. Nesse sentido a experiência vivida no próprio corpo não separa o Eu e o Mundo, mas configura "uma forma específica de ser presentemente no mundo", conforme Fritsch. ${ }^{16}$ (p.47).

Essas ideias estão associadas aos elementos da dança contemporânea. A proposta de renovação da Dança Moderna balizada pela busca de novos repertórios de movimento é redimensionada na Conexões: revista da Faculdade de Educação Física da UNICAMP, Campinas, v. 9, n. 2, p. 110-129, maio/ago. 2011. ISSN: 1983-9030 
dança contemporânea a partir da co-existência de infinitas estéticas dançadas. Essas estéticas refletem as histórias e crenças de cada dançarino e a valorização dessas. Busca-se a "autoria" da dança, isto é, é menos requerido um repertório comum de movimentos e mais a singularidade desses e de ideias que dão forma aos processos dançados, sendo estes, outra característica desse modo de fazer e pensar a dança na atualidade. Nesse sentido, a coreografia como produto final dá espaço ao produto processual, ou seja, a dança está constantemente sendo repensada e recriada. Nisso, conforme aponta $\operatorname{Hercoles}^{17}$ (s/p), “o modelo da repetição é substituído pela construção da ação a partir da singularidade da implementação, abrindo brechas de reflexão em coisas constituídas, não mais se tratando da simples reprodução de algo que está pronto”.

Transferindo essas ideias para a escola, pensamos que esses novos entendimentos ampliam, consideravelmente, as possibilidades da dança ganhar espaço nesse contexto. Pensar que é possível construir dança a partir do repertório individual de movimento e que os sujeitos vão constituindo seus próprios sentidos e significados, possibilita pensar nos inúmeros conhecimentos que podem ser produzidos, tanto no nível da dança, quanto do sujeito e do mundo. Além disso, devemos pensar que a dança, quando voltada à ampliação das sensibilidades e desbloqueio das potencialidades humanas, na perspectiva da educação estética (Saraiva-Kunz ${ }^{1}$ ), permite a descoberta de limites e possibilidades de movimento, contribuindo para uma leitura ampliada de si próprio e do mundo.

Retomando o princípio de que a dança não é algo que acontece de forma isolada do contexto na qual é construída torna-se importante percebê-la e trabalhá-la como forma de apreensão do mundo e que, a partir dos elementos que constituem um processo coreográfico, seja possível (re)inventar soluções corporais para que essas reflexões ganhem cena. É preciso ressaltar que 
essa possibilidade somente poderá materializar-se sob a ótica de um trabalho que priorize a história e potencialidades corporais individuais, dando conta de produzir conhecimentos inerentes à própria dança, e que busque, sobretudo, produzir conhecimentos a cerca do próprio sujeito-dançante e do mundo do qual esse faz parte.

Nesse sentido, o Quadro 1 abaixo sintetiza as ideias apresentadas até então, tentando explicitar os diferentes conhecimentos que podem ser constituídos/adquiridos a partir das escolhas tomadas no processo de ensinar e aprender dança, já que essas escolhas representam determinadas formas de leitura e apreensão do mundo.

Quadro 1 - Diferenciações entre as perspectivas de dança em relação aos conhecimentos produzidos/apreendidos

\begin{tabular}{|c|c|c|c|}
\hline $\begin{array}{l}\text { Conhecimentos } \\
\text { produzidos/ } \\
\text { adquiridos em } \\
\text { relação à }(0)\end{array}$ & Balé Clássico & Dança Moderna & Dança Contemporânea \\
\hline Corpo & $\begin{array}{l}\text { Rígido; fechado; } \\
\text { voltado para a } \\
\text { verticalidade. }\end{array}$ & $\begin{array}{l}\text { Busca da energia vital; a } \\
\text { reconciliação com a terra; a } \\
\text { natureza humana. }\end{array}$ & $\begin{array}{l}\text { Autônomo; híbrido; complexo; } \\
\text { busca o diálogo e comunicação. }\end{array}$ \\
\hline Movimento & $\begin{array}{l}\text { Determinados; } \\
\text { codificados; } \\
\text { controlados. }\end{array}$ & $\begin{array}{l}\text { Soltura corporal; busca das } \\
\text { possibilidades individuais; } \\
\text { novas referências espaciais. }\end{array}$ & $\begin{array}{l}\text { Inúmeras } \quad \text { possibilidades de } \\
\text { movimento; } \\
\text { referências; Ausência de um padrão } \\
\text { técnico. }\end{array}$ \\
\hline Sujeito & $\begin{array}{l}\text { Disciplinado para a } \\
\text { obediência. }\end{array}$ & $\begin{array}{l}\text { Problematizador } \\
\text { realidade vigente. }\end{array}$ & $\begin{array}{l}\text { Com capacidades criativas } \\
\text { múltiplas; Autor de suas danças; } \\
\text { conexão com várias áreas do } \\
\text { conhecimento; } \\
\text { experiências. }\end{array}$ \\
\hline Dança & $\begin{array}{l}\text { Reprodução de passos } \\
\text { ensinados por terceiros. } \\
\text { Enfase no produto } \\
\text { final. }\end{array}$ & $\begin{array}{l}\text { Espaço para } \\
\text { problematização } \\
\text { discussões do seu tempo e } \\
\text { de criação de novas técnicas. } \\
\text { Dançarinos/ criadores } \\
\text { referenciam suas próprias } \\
\text { técnicas na autoria de suas } \\
\text { danças. }\end{array}$ & $\begin{array}{l}\text { Espaço para problematização e } \\
\text { discussões do seu tempo. Estéticas } \\
\text { múltiplas; Reconhecimento da } \\
\text { individualidade como possibilidade } \\
\text { de movimento; Ênfase no processo. }\end{array}$ \\
\hline Sociedade & $\begin{array}{l}\text { Manutenção da ordem } \\
\text { e das hierarquias, do } \\
\text { status quo. }\end{array}$ & $\begin{array}{lrr}\text { Mudanças } & \text { das } & \text { dinâmicas } \\
\text { sociais: } & \text { interesse } & \text { e } \\
\text { preocupação } & \text { com } & \text { as }\end{array}$ & $\begin{array}{l}\text { Valorização e reconhecimento da } \\
\text { diversidade humana. }\end{array}$ \\
\hline
\end{tabular}


As ideias sistematizadas acima apontam para algumas questões que precisamos considerar quando no trabalho com a dança, especialmente, no contexto formal de educação, já que as nossas posições sobre o "pôrque" ensinar dança na escola e sobre "o quê" ensinar/aprender ao fazer dança, delimitam os contornos que damos a essa prática.

Sendo assim, entendemos que a dança na escola, no contexto da educação física escolar, deve ser trabalhada na perspectiva sinalizada anteriormente, qual seja, a de potencializar as capacidades individuais, visando o afloramento das capacidades expressivas e criativas do sujeito que dança. Apesar do empenho realizado por alguns pesquisadores, nas últimas três décadas, para compreender o corpo e o movimento para além das suas condições biológicas e biomecânicas, ainda predominam nas práticas corporais a ideia de rendimento e eficiência técnica, saberes construídos sob as premissas da ciência moderna. Brasileiro e Marcassa ${ }^{18}$ afirmam que as explicações da fisiologia do exercício e da medicina precisam ser relativizadas como únicas verdades no campo acadêmico da educação física "até porque têm sido elas as responsáveis pelo fornecimento de conhecimentos, instrumentos e técnicas de manipulação, mutilação, artificialização e coisificação do corpo". ${ }^{18}$ (p. 197).

Concordamos com as autoras que essa visão restrita do corpo e do movimento, não dá conta de compreender a complexidade do sujeito em movimento quando nas vivências das práticas corporais. Ao realizarmos um movimento numa situação de jogo, esporte, luta ou dança não é suficiente visualizar a mecânica do gesto, mas sim toda a intencionalidade imbricada nesse, além dos fatores psíquicos, afetivos e sociais. Nisso, torna-se essencial, como afirmam as autoras $^{18}$

Conexões: revista da Faculdade de Educação Física da UNICAMP, Campinas, v. 9, n. 2, p. 110-129, maio/ago. 2011. ISSN: 1983-9030 
pensar sobre o corpo, os movimentos, os gestos, os comportamentos, assim como o esporte, a ginástica, a dança e as demais práticas corporais, como manifestações culturais expressivas, como linguagens participantes da vida social, na construção de saberes, valores, ações, sentidos e significados, comportamentos e relações humanas. (p. 197).

Nesse caminho, o entendimento de aprender/fazer dança é mais do que aprender/decorar sequências de movimentos codificados e padronizados; é um lançar-se no universo do movimento, a partir das capacidades criativas e expressivas exploradas como possibilidade de diálogo do sujeito com seu mundo, como afirma Kunz, ${ }^{19}$ o que deverá ser providenciado pelos currículos escolares.

\section{REFLEXÕES FINAIS...}

Pensamos que a clareza dos conhecimentos que podem ser construídos/adquiridos a partir das diferentes formas de fazer dança nos ajudam a trilhar o caminho dessa prática no contexto educacional, sendo possível identificar que algumas posições comprometem a educação que visa a formação de um sujeito criativo, expressivo e crítico.

Por isso, visualizar na dança saberes imprescindíveis para o processo de formação humana como aqueles ligados ao conhecimento sensível, tanto de si como do mundo, torna-se condição fundamental, já que parte daquilo de mais essencial ao sujeito: seu corpo em movimento.

Assim, para nós professores, fica sempre presente o compromisso de avaliarmos, conforme aponta Fortin, ${ }^{8}$ quais valores são suscetíveis de guiar o processo de construção da dança, bem como de avaliarmos que papel o sujeito-dançante é chamado a desempenhar, para que essa prática, além de constituir-se numa outra forma de ser e estar no mundo, seja um espaço de apreensão e questionamento do mundo-vivido.

Conexões: revista da Faculdade de Educação Física da UNICAMP, Campinas, v. 9, n. 2, p. 110-129, maio/ago. 2011. ISSN: 1983-9030 


\section{REFERÊNCIAS}

${ }^{1}$ SARAIVA-KUNZ, M. C. Dança e gênero na escola: formas de ser e viver mediadas pela educação estética. 2003. Tese (Doutorado) - Faculdade de Motricidade Humana, Universidade Técnica de Lisboa, Lisboa, 2003.

${ }^{2} \mathrm{ABR}$ ÃO, E. et al. Imagens e percepção da dança: da estética formal à expressão estética. In: SILVA, A. M.; DAMIANI, I. Práticas corporais: construindo outros saberes em educação física. Florianópolis: Nauemblu Ciência \& Arte, 2006. p. 84-99.

${ }^{3}$ KLEINUBING, N. D. A dança como espaço-tempo de intersubjetividades: possibilidade da educação física no ensino médio. 2009. Dissertação (Mestrado) - Universidade Federal de Santa Catarina, Florianópolis, 2009.

${ }^{4}$ MONTEIRO, M. Balé, tradição e ruptura. In: PEREIRA, R.; SOSTER, S. (Org.). Lições de dança, Rio de Janeiro, n. 1, p. 169-189, 1999.

${ }^{5}$ PORTINARI, M. História da dança. Rio de Janeiro: Nova Fronteira, 1989.

${ }^{6}$ SANTOS, B. S. Pela mão de Alice: o social e o político na pós-modernidade. 4. ed. São Paulo: Cortez, 1997. 
${ }^{7}$ SANTOS, B. S. Um discurso sobre as ciências. 6. ed. Porto: Afrontamento, 1993.

${ }^{8}$ FORTIN, S. Transformação de práticas de dança.. Lições de dança, Rio de Janeiro, n. 4, p. 161-173, 2004.

${ }^{9}$ STRAZZACAPPA, M. Reflexões sobre a formação profissional do artista da dança. Lições de dança, Rio de Janeiro, n. 4, p. 175-194, 2004.

${ }^{10}$ HOUAISS, A. Dicionário da língua portuguesa. 2 ed. rev. aum. Rio de Janeiro: Objetiva, 2004.

${ }^{11}$ ALVES, L. G.; SARAIVA, M. C. Autoridade na dança: reflexões iniciais a partir de um referencial histórico-crítico. In: SEMINÁRIO DE EPISTEMOLOGIA E TEORIAS DA EDUCAÇÃO, 3., 2008, Campinas. COLÓQUIO DE EPISTEMOLOGIA DA EDUCAÇÃO FÍSICA, 4., 2088, Campinas. Anais ... Campinas, 2008.

${ }^{12}$ CANTON, K. A pulsação do nosso tempo. Disponível em: http://www.superzap.com.br/artecultura/a-pulsacao-do-nosso-tempo.html. Acesso em: 15 abr. 2007.

${ }^{13}$ MORIN, E. Os sete saberes necessários à educação do futuro. 5. ed. São Paulo: Cortez, 2002.

${ }^{14}$ SARAIVA, M. C. O sentido da dança: arte, símbolo, experiência vivida e representação, Movimento, Rio Grande do Sul, v. 11, n. 3, p. 219-241, set./dez. 2005. 
${ }^{15}$ LEPECKI, A. O corpo colonizado. Gesto: revista do Centro Coreográfico do Rio, rio de Janeiro, n. 2, p. 6-11, jun. 2003.

${ }^{16}$ FRITSCH, U. Tanz, bewegungskultur, gesellschaft. Verluste und chancen symbolischexpressiven bewegens. Frankfurt: Afra Verlag, 1988.

17 HERCOLES, R. Dança como produção de conhecimento. Disponível em: http://idanca.net/lang/pt-br/2008/02/21/epistemologia-em-movimento/5229/. Acesso em 12 dez. 2009.

${ }^{18}$ BRASILEIRO, L. T.; MARCASSA, L. P. Linguagens do corpo: dimensões expressivas e possibilidades educativas da ginástica e da dança. Pro-Posições, Campinas, v. 19, n. 3, p. 195207, set./dez. 2008.

${ }^{19}$ KUNZ, E. Pedagogia do esporte, do movimento humano ou da educação física? In: KUNZ, E.; TREBELS, A. H. (Org.). Educação Física crítico-emancipatória: com uma perspectiva da pedagogia alemã do esporte. Ijuí: Ed. da Unijuí, 2006. 